\title{
INOVAÇÕES NO SETOR PÚBLICO: RELATO DE EXPERIÊNCIAS
}

\author{
João Francisco Sarno Carvalho* \\ Rafaelle Stefane Elias Alves** \\ Wilker Carvalho dos Santos*** \\ Habib Ribeiro David ${ }^{* * * *}$ \\ Fernanda da Silva Souza*****
}

RESUMO: Este artigo tem como objetivo apresentar as principais características de alguns experimentos destaques nos processos e produtos inovadores existentes no âmbito da administração pública, utilizados por municípios, Estados e União. $\mathrm{O}$ referido estudo busca compreender como se materializam as inovações propostas ao aumento de eficiência, transparência e celeridade nos processos públicos e descrever experiências inovadoras, demonstrando suas peculiaridades, importância e diferencial que promoveram dentro do setor público em que estão sendo aplicadas. O artigo apresenta como exemplo de estudo o Sistema Eletrônico de Informação SEI, o Dataviva e o Sistema Mineiro de Inovação - Simi, casos de sucessos de inovação no setor público. Ao final, identificou-se que a inovação no setor público impõe uma série de limitações que precisam ser superadas para se tornar efetivo, sendo fundamental estimular a inovação no setor público, por meio de ações objetivas envolvendo parcerias entre administração pública, pesquisadores, universidades e demais atores da sociedade.

PALAVRAS-CHAVE: Inovação no setor público; Experiências de inovação; SEI; Dataviva; Simi.

\footnotetext{
"Doutorando em Inovação Tecnológica e Propriedade Intelectual pela Universidade Federal de Minas Gerais (UFMG), Belo Horizonte, Brasil. E-mail: jfsarcar@gmail.com

** Bacharel em Gestão Pública (UFMG), Belo Horizonte, Brasil. Pós-graduação em Gestão Pública e Desenvolvimento Regional (IFMG), Brasil.

*** Especialista em Controladoria pela Faculdade Venda Nova do Imigrante, Venda Nova do Imigrante (ES), Brasil. Analista Administrativo da Fundação de Amparo à Pesquisa do Estado de Minas Gerais.

**a** Especialista em Advocacia Criminal pela Escola Superior de Advocacia da Ordem dos Advogados do Brasil (OAB), Belo Horizonte, Brasil. Presidente da OAB de Ribeirão das Neves (MG), Brasil.

****** Pós-graduanda em Gestão Pública e Desenvolvimento Regional, Brasil.
} 


\section{INNOVATION IN THE PUBLIC SECTOR: REPORT OF EXPERIENCES}

ABSTRACT: Current paper provides the main characteristics of relevant experiments in innovatory processes and products within public administration used at the municipal, state and federal levels. Investigation analyzes the manner innovations for increase in efficiency, transparency and fastness in public processes are put in practice. They reveal the peculiarities, importance and differences that they trigger within the public sector where they are applied. The Electronic Information System (SEI), Dataviva and Mineiro Innovation System (SIMI) are analyzed as innovation successes within the public sector. Innovation within the public sector imposes a series of limitations that should be overcome to become effective. It is crucial to stimulate innovation in the public sector through activities which involve joint ventures between public administration, researchers, universities and other agents.

KEY WORDS: Innovation of the public sector; Experiences of innovation; SEI; Dataviva; Simi.

\section{INTRODUÇÃO}

Os impactos políticos, sociais e econômicos da inovação têm sido tema de destaque na atualidade, com grande evidência para as inovações oriundas do setor privado. Nesse contexto, as dinâmicas de inovação no setor público também têm tido destaque, isso porque, ao longo do tempo, o Estado deixa de ser visto apenas como incentivador das inovações privadas e passa a assumir um papel estratégico na regulação das relações econômicas e no provimento de serviços e políticas públicas inovadoras à sociedade.

Os estudos relacionados ao tema emergiram a partir do início do século XX. Apesar das bases teóricas de inovação se concentrarem majoritariamente no setor privado, é importante ressaltar que a aplicação da inovação tem características distintas com relação ao setor público, cujos processos inovadores encontram algumas complexidades relacionadas à finalidade das atividades do Estado. Desse modo, é possível encontrar na literatura disponível uma relevante base teórica que abrange o conceito dentro da gestão pública (OLIVEIRA et al., 2015; MULGAN; ALBURY, 2003; SPINK, 2006; POTTS, 2010; BRANDÃO, BRUNO-FARIA, 2013). 
Em análise aos preceitos da inovação no contexto brasileiro, é notável um desafio em criar uma conceitualização da inovação que se aproxime da realidade com base nas experiências vivenciadas pelas organizações. A grande questão é compreender como se materializam as inovações propostas ao aumento de eficiência, transparência e celeridade nos processos públicos. Para isso, o objetivo deste estudo é responder à seguinte pergunta: Quais são as especificidades das inovações utilizadas atualmente no setor público? Nesse aspecto, o artigo pretende explorar as principais características de alguns experimentos destaques nos processos e produtos inovadores existentes no âmbito da administração pública, utilizados por municípios, Estados e União.

Para galgar o objetivo traçado e responder à pergunta norteadora, o artigo, além da introdução, conta com mais seis seções, sendo que a segunda aborda a descrição dos métodos utilizados no trabalho; já a terceira faz uma contextualização teórica com objetivo de caracterizar a inovação no setor público e delimitar as tipologias e paradigmas relacionados à inovação; da quarta à sexta seção, são apresentados alguns dos resultados da pesquisa, bem como a descrição detalhada das experiências de produtos e serviços analisados; por fim, a discussão é encerrada com as considerações finais.

\section{METODOLOGIA}

A metodologia de investigação do presente trabalho foi elaborada para elucidar a pergunta norteadora. Para delineamento da pesquisa, mostrou-se essencial a utilização do procedimento da pesquisa bibliográfica para o melhor entendimento sobre o tema e verificar como a literatura está abordando a inovação na esfera pública.

Gil (1999, p. 65) destaca a importância da pesquisa bibliográfica:

A pesquisa bibliográfica é desenvolvida a partir de material já elaborado, constituído principalmente de livros e artigos científicos. Embora em quase todos os estudos seja exigido algum tipo de trabalho desta natureza, há pesquisas 
desenvolvidas exclusivamente a partir de fontes bibliográficas $[\ldots]$.

[...] A principal vantagem da pesquisa bibliográfica reside no fato de permitir ao investigador a cobertura de uma gama de fenômenos muito mais ampla do que aquela que poderia pesquisar diretamente.

Dessa forma, ao pesquisarmos, com auxílio de palavras-chaves, por exemplo: Inovação, Experiências inovadoras, Inovação no setor público, selecionamos materiais que atendessem o objetivo do trabalho e utilizamos artigos científicos publicados em periódicos online e em sites de pesquisa acadêmica, além de coleta de informações em sites oficiais dos portais que utilizam a inovação, como ENAP (Escola Nacional da Administração Pública), INOVAGOV (Rede de inovação do setor público).

Após essa etapa, é perceptível que há uma gama de materiais que aborda o tema no setor privado. Isso indica a necessidade de serem exploradas e fomentadas pesquisas que dizem das experiências e da importância da inovação no âmbito público.

Os trabalhos selecionados foram somente em português do Brasil e, após uma leitura prévia de todo material, foram mantidos aqueles que eram compatíveis com o delineamento da pesquisa.

Nas duas primeiras seções do trabalho, optamos por buscar artigos que detalhassem a definição de inovação, para que fosse possível trazer as suas especificidades da gestão pública. Embora se tenha uma ideia de que inovar é uma prática habitual apenas no setor privado, concluímos que esse é um cenário que está passando por mudanças, conforme será demonstrado nas seções seguintes.

Nas seções que abordam as experiências inovadoras, foi possível detalhar como o setor público está buscando inovar e valorizar essa prática. Assim, o nível de pesquisa descritiva se mostrou eficiente para a exposição das experiências.

Cumpre destacar que a descrição foi inspirada nas leituras das experiências contidas nas bibliografias coletadas, sem que tenham sido vivenciadas pelos autores. O objetivo é descrever as experiências selecionadas demonstrando suas peculiaridades, importância e diferencial que promoveram dentro do setor público em que estão sendo aplicadas. 


\section{INOVAÇÃO NO SETOR PÚBLICO: GÊNESE E DEFINIÇÃO}

Os anos 60 deram início a um fenômeno denominado era do conhecimento. Durante esse período, um conjunto de evoluções tecnológicas, associadas à corrida armamentista dos países e ao investimento em bases aeroespaciais, culminaram no surgimento da indústria microeletrônica. Todos esses fatos forneceram bases materiais para o desenvolvimento do fenômeno político-econômico conhecido como globalização.

A internacionalização do comércio advinda da globalização inaugurou um grande alargamento do fluxo de inovações e uma maior expansão do potencial de comunicação que impactou a sociedade de uma maneira geral. Diante disso,

Com uma velocidade sem precedentes na história da humanidade, tecnologias sofisticadas e baratas aliadas a custos de comunicação em queda vão criando uma nova sociedade, articulada em rede, tendo o conhecimento como insumo líder, na qual os governos obrigatoriamente deverão se inserir sob pena de perda de representatividade com todos os riscos que tal fato traz para a própria democracia (AGUNE et al., 2014, p. 54).

Nesse ínterim de avanços tecnológicos, surge um amplo campo de estudos que tem como principal objetivo a observação das transformações da sociedade advindas das inovações, em especial ao que se refere ao desenvolvimento do potencial econômico dos governos.

\subsection{CARACTERÍSTICAS DA INOVAÇÃO}

Com a expansão do capitalismo, a inovação esteve no cerne do debate e impulsionou a criação de várias teorias sobre o tema. Segundo Brandão e Bruno-Faria (2013), os estudos pioneiros se pautaram na relação entre inovação tecnológica e desenvolvimento econômico com foco no desenvolvimento de produtos e processos do setor privado.

Schumpeter (1997), um dos autores precursores do assunto, relacionou 
o desenvolvimento econômico e inovação, sob a perspectiva do capitalismo tecnológico, através da criação de novos mercados e de ações empreendedoras. Ao citar a "destruição criadora", ou seja, a permutação de antigos produtos e hábitos de consumir por novos, foi um direcionamento que Schumpeter rapidamente deu ao retratar o processo do desenvolvimento econômico.

A teoria de desenvolvimento econômico, elaborada por Schumpeter (1997), trouxe a diferenciação entre os conceitos de invenção e inovação; segundo ele, a invenção trata-se de uma ideia ou esboço para um novo ou aprimorado processo, produto ou serviço, já a inovação é, na perspectiva econômica, um processo completo quando existe uma transação comercial com uma invenção que gere acúmulo de capital.

O conceito de inovação para esse autor é tipificado por novo produto e novo processo de produção. Além disso, em sua teoria, "a inovação é descrita como novas combinações entre materiais e forças produtivas a fim de viabilizar novos produtos e o desenvolvimento econômico, e esse processo dinâmico de substituição de antigas tecnologias por novas é denominado "destruição criadora". (BRANDÃO; BRUNO-FARIA, 2013, p. 229).

Brandão e Bruno-Faria (2013) entendem, de uma forma geral, que o menor requisito para se definir uma inovação é o fato de ela ser inédita ou significativamente melhorada para organização. Nesse processo, estão inclusos os processos, produtos e métodos adotados pelas organizações, de forma pioneira aqueles que foram aderidos de outras organizações. Um aspecto de destaque é a implantação da ideia ou prática para se validar uma inovação.

$\mathrm{Na}$ concepção da Organização para Cooperação e Desenvolvimento Econômico (OCDE), que representa uma referência global sobre o tema, a inovação é compreendida como um processo ou produto novo ou melhorado, e foi submetida a uma sistematização pelo Manual de Oslo, que a classificou em quatro tipos: inovação de produtos, inovação de processos, inovação organizacional e inovação por marketing (OLIVEIRA et al., 2015).

A partir dessa abordagem, a OCDE (ORGANIZAÇÃO PARA A COOPERAÇÃO E DESENVOLVIMENTO ECONÓMICO, 2005) teve como objetivos elementares preparar as empresas para potencialidades do futuro, além de "[...] garantir a 
competitividade, ou representatividade no caso dos governos, das organizações em um mundo globalizado e altamente volátil" (CARLOS, 2014, p. 64).

Diante do exposto, é válido ressaltar que a inovação não é exclusividade do setor privado, pois, na atualidade, cada vez mais atores políticos têm o desafio de responder às demandas da sociedade em complexos ambientes. Para contornar esse cenário, incentivam políticas inovadoras no âmbito dos dois setores fomentando a competitividade das organizações com vistas do aumento da eficácia e eficiência.

\subsection{ESPECIFICIDADES DA INOVAÇÃO NO SETOR PÚBLICO}

Os estudos sobre inovação no setor público são considerados recentes, e abarcam uma diversidade de explicação entre os teóricos do tema. O que é possível afirmar na atual conjuntura é que grande parte das inovações no setor público não são radicais nem sistêmicas, mas pequenas alterações nos processos promovidas por agentes públicos em prol da melhoria dos serviços prestados, conforme Brandão e Bruno-Faria (2013).

Santos e Sano (2016) pontuam que a inovação no setor público vem sendo construída com raízes de sua definição no setor privado, que constitui o berço de emergência do conceito; entretanto, também ressaltam que é necessária cautela aos limites de transferência de conceitos do setor privado, uma vez que, na esfera pública, a inovação concentra-se no acompanhamento de mudanças nas organizações e ou no desenvolvimento de políticas públicas.

Nessa perspectiva, a inovação é trabalhada numa visão holística onde são considerados os elementos não apenas econômicos do processo de inovação, mas também os organizacionais, institucionais, sociais e políticos, bem como os fatores e mecanismos relacionais. Entende-se que a inovação não é um processo linear começando em universidades e laboratórios do governo e, em seguida, transferido por meio de empresas ao mercado, mas sim processos iniciados dentro da empresa na busca e resolução de um problema (SANTOS; SANO, 2016, p. 6). 
De acordo com Mulgan e Albury (2003), a inovação como tema estratégico no setor público pode ser definida como a formação e a implementação de novos produtos, processos, serviços e métodos de entrega que resultem em uma considerável melhoria na qualidade dos objetivos.

O estímulo da inovação no setor público no âmbito econômico perpassa na concepção de Potts (2010) por três razões: a primeira é que, em grande parte dos países que compõem a OCDE, o setor público exerce papel-chave na dinâmica macroeconômica, influenciando diretamente no PIB; a segunda razão diz respeito ao potencial da inovação em resolver impasses na sociedade; por fim, a terceira razão refere-se ao potencial de definição de políticas que impactam na inovação do setor privado.

De forma distinta ao setor privado, em que os incentivos à inovação resultam em uma busca da maximização do lucro, a inovação no serviço público tem como resultados os ganhos para sociedade. Não obstante, o Estado assume uma dupla responsabilidade; de um lado, representa o papel de agente facilitador e indutor das atividades privadas através das políticas; já em outra face, o Estado é um agente econômico de grande peso, atuando nas mais diversas áreas, conforme ressaltam Oliveira et al. (2015).

Halvorsen (2005) apresenta algumas tipologias interessantes para a inovação pública, dentre as quais se destacam:

- um serviço novo ou melhorado;

- inovação de processo;

- inovação administrativa (como o uso de um novo instrumento político, que pode ser resultado de mudança de política);

- inovação do sistema (novo sistema ou mudança fundamental de um sistema existente);

- inovação conceitual (mudança na perspectiva dos atores);

- mudança radical de racionalidade.

Dentre algumas especificidades do setor público, Oliveira et al. (2015, p. 14-15) afirmam que: 
É certo que, no caso das inovações no setor público, algumas especificidades que caracterizam fortemente o ambiente desse setor devem ser destacadas. Inicialmente, os aspectos relacionados a legalidade e impessoalidade são mais presentes no setor público do que no setor privado, sujeitos, muitas vezes, a estruturas administrativas familiares. Outro elemento importante, e característico do setor público, é sua rigidez estrutural, a qual é muito menos propensa a adequações do que no setor privado.

Outro aspecto relevante para compreensão do fenômeno de inovação é a necessidade de analisar de maneira holística o sistema de aspectos institucionais e organizacionais que envolvem interferências do ambiente externo como, por exemplo, oscilações econômicas e mudanças do ambiente interno, como variações de tamanho da organização. A implementação de inovação está sujeita a elementos como custo, impactos futuros e complexidade, conforme Brandão e Bruno-Faria (2013).

Diante do exposto, é nítido que o conceito de inovação é complexo e incremental, a depender da esfera pode assumir características específicas. Na esfera pública, a inovação deve estar alinhada, sobretudo, com os preceitos constitucionais e, primordialmente, com os interesses do bem comum.

\section{PARADIGMAS DA INOVAÇÃO NO SETOR PÚBLICO}

Antes de adentrar especificamente aos tipos de inovação no setor público, conforme trabalhados pela doutrina especializada, é preciso salientar que o entendimento acerca do papel da inovação no setor público e a forma como ela é realizada são influenciados pelos paradigmas da administração pública.

Tais modelos são subdivididos em: paradigma patrimonialista; paradigma burocrático; paradigma da nova gestão; e paradigma do novo serviço público.

No paradigma patrimonialista, o soberano organiza o poder de forma análoga ao poder exercido em sua casa. Não há uma especialização profissional e a seleção dos empregados é feita a partir do círculo pessoal do administrador. É uma forma de dominação tradicional. Com o advento do capitalismo e da democracia, 
houve a necessidade de um novo paradigma capaz de combater a corrupção, o uso dos recursos públicos como se privados fossem e o nepotismo.

O paradigma burocrático é baseado nos princípios do modelo ideal de Max Weber, com foco na eficiência e despolitização das questões sociais. Veio para substituir a força do poder exercido por regimes autoritários.

Helal e Diegues (2009, p. 26) colocam que "A grande expectativa em torno da Administração Pública Burocrática refere-se à necessidade de conseguir controlar o conteúdo da ação governamental, impedindo que os políticos agissem contra os interesses coletivos da comunidade".

Tal fato ocorre em tese porque é possível antever um detalhamento de como os atos administrativos devem ser realizados.

Entretanto, com o aumento dos serviços sociais e econômicos assumidos pelo Estado, desenvolvimento tecnológico e globalização da economia surge a necessidade de nova mudança de paradigma.

Importante notar que, na década de 80 , havia uma tendência mundial de agregar esforços para modernizar e agilizar a administração pública como um todo. O New Public Management se tornou um importante conjunto de ideias norteadoras dessas mudanças.

Nesse contexto, abriu-se espaço para que a Nova Gestão Pública pudesse ganhar campo da tradicional organização burocrática. Castro (2016, p. 58) afirma que

No início da década de 1990, foi moldado principalmente em termos de Nova Gestão Pública, com foco na privatização dos serviços públicos, gestão de desempenho e melhoria de serviços públicos. Nas últimas duas décadas, os defensores da Nova Gestão Pública têm afirmado que o setor público deve imitar ou aprender com o setor privado.

E conclui que

O setor público deve ser mais inovador, flexível e eficiente através da introdução de uma concorrência baseada no mercado e técnicas de gestão do setor privado e, quando as empresas públicas estão presentes em setores econômicos em que competem diretamente com empresas privadas, estas tendem a ser mais inovadoras. 
O paradigma da nova gestão pública adota o modelo gerencial, com foco na eficácia e qualificação com o fito de ampliar a qualidade do serviço público prestado à sociedade e à redução de custos da máquina pública.

Hoffman e Klumb (2016) afirmam que esse modelo sofreu diversas críticas, já que a formulação de políticas públicas permanecia sob o monopólio de uma elite burocrática, em virtude da prevalência do ideal, limitando assim a participação da sociedade na estrutura governamental.

Assim, com a crise do modelo anterior, surgem os paradigmas do novo serviço público e da nova governança pública, que buscam uma reformulação do Estado com uma gestão mais participativa.

Hoffman e Klumb (2016, p. 86) mostram que a ascensão desses paradigmas pode gerar uma série de oportunidades de inovação, e prosseguem

As crescentes demandas por serviços públicos, mais responsivos, transparentes, sustentáveis e democráticos requerem das organizações novos modelos de gestão, novos processos e formas de comunicação que as tornem aptas a desenvolver e oferecer à sociedade esse novo padrão de serviços.

Conforme visto, ao longo do tempo, há uma importante variação no modo como a inovação é vista e aplicada pelo serviço público de acordo com as mudanças na sociedade de modo geral.

A percepção da evolução dos paradigmas da inovação é importante para entender os diversos tipos de inovação existentes, segundo a doutrina especializada.

\section{A ESTRUTURAÇÃO DE INOVAÇÃO DO SETOR PÚBLICO}

Como apontado nos capítulos anteriores, ainda que a inovação no setor público seja um tema pouco explorado pela literatura, há forte tendência de crescimento em pesquisas e compartilhamentos de ideias criativas para a solução de problemas identificados dentro dos órgãos públicos. 
Inovar em um cenário de escassez de recursos parece ser inviável, trazendo à tona o discurso de que o setor público não teria condições de buscar novas formas para transformar sua organização, sendo fortalecida a afirmativa de que inovar cabe ao setor privado. Assim, Dias (2014, p. 120) confirma que "[...] as limitações enfrentadas pelo setor público fazem nascer a necessidade de inovar, desconstruindo assim a premissa de que inovação é inteiramente privada”.

Para atingir o objetivo de se alcançar a modernização, eficiência, eficácia e qualidade para as organizações, são essenciais criar formas de fomentar ações inovadoras dentro do setor público, envolvendo os servidores para que esse paradigma seja superado.

Nesse passo, o Ministério do Planejamento (MP), que possui a responsabilidade de organizar o sistema de inovação da administração pública federal, com o propósito de modernizar as instituições e os órgãos públicos, causando um impacto positivo para a população que utilizam serviços prestados por esses entes públicos, criou, em 2015, o Inova, uma unidade para conduzir ações na temática da inovação na gestão pública (FARIA et al., 2017).

Diante o exposto, o MP, percebendo que inexiste no Brasil uma forma de inovar-se sistematicamente, com o objetivo de compartilhamento de experiências que envolvam pessoas e organizações públicas interessadas pela temática, desenvolveu a rede Inovagov, composta por um conjunto de organizações dos setores público, privado, acadêmico e terceiro setor. Possibilitando assim, fomentar, estimular, viabilizar a inovação no âmbito do setor público.

No primeiro encontro promovido pela Inovagov, em março de 2016, estando presentes no evento representantes de instituições públicas federais, avaliaram como se daria o funcionamento da rede, definindo que

1) A rede deve integrar e estimular arranjos para a inovação no setor público por meio da conexão de múltiplos atores com interesse no tema. A InovaGov é um sistema dinâmico que interage de forma não linear, auto-organizada, autônoma, colaborativa, adaptativa, ágil, flexível e por autoaprendizagem. Os atores da rede se movem por conhecimento (intuitivo ou não), confiança, interesses próprios, objetivos e valores comuns, de forma alinhada - motivados pela necessidade de 
cooperação e comprometidos com suas missões.

2) A InovaGov é formada por organizações do setor público, do setor privado, da sociedade civil e do setor acadêmico interessadas em inovação no setor público e em promover o intercâmbio de conhecimentos e experiências, na identificação de boas práticas e no auxílio mútuo para solução de problemas.

3) São (ou serão) produtos/serviços da InovaGov: a conexão de atores; a realização de encontros e atividades; o estabelecimento de uma rede de laboratórios de inovação; o desenvolvimento de um observatório de experiências em inovação; a criação e a divulgação de um boletim/revista de informações; a busca de formas de financiamento de projetos de inovação; a coleta e a premiação de soluções para a gestão pública; a consolidação de guias de ferramentas e métodos de inovação; o desenvolvimento de programas de capacitação; o desenvolvimento e a difusão de pesquisas e estudos de casos; e a criação de um portfólio de soluções tecnológicas para inovações testadas. (FARIA et al., 2017, p. 242-243).

Essas premissas basicamente visam nortear colaboradores sobre as ações da Inovagov, reforçando a importância de fortalecer a cultura da inovação no setor público, criando materiais, discussões que criam soluções criativas para os desafios identificados nas organizações, proporcionando compartilhamento de experiências.

Para além de tratar como se constituiu o funcionamento da rede, Faria et al. (2017) apontam os desafios que os membros do Inova devem tratar prioritariamente, como criar "plataforma de colaboração e instrumento de comunicação da rede, promover concursos e prêmios de inovação, metodologias de inovação e análise, avaliação de custos e impactos de projetos de inovação". Esses desafios apontados precisam ser superados para que se dê início aos tralhados da rede de inovação e, mesmo que essa temática não esteja enraizada no setor público, é necessário, ainda, que os participantes sejam pessoas comprometidas e interessadas em colaborar com a modernização das organizações.

Embora a Rede tenha impactos indiscutivelmente positivos, como o compartilhamento de metodologias, informações e conhecimentos, ferramentas e boas práticas, bem como conquista de apoio de outros órgãos e um bom 
aproveitamento intelectual, nota-se que, ainda, há uma resistência de adoção à inovação, motivada pela sensação de insegurança em compartilhar informações com outros setores, principalmente com atores externos (FARIA et al., 2017).

Diante dos resultados positivos, a rede obteve a colaboração de outras instituições, como a ENAP (Escola Nacional de Administração Pública) e do Serviço Florestal Brasileiro, motivados pela parceria firmada entre o Inova e a União Europeia. Essa parceria se deu através do patrocínio do Ministério do Desenvolvimento, Indústria e Comércio (MDIC).

Inicialmente, as organizações aderiam ao Inovagov informalmente; contudo, fez-se necessário que o MP assinasse uma ACT com o Tribunal de Contas da União (TCU) e o Conselho de Justiça Federal (CJF), com o objetivo de formalizar as parcerias e proporcionar maior segurança para os servidores que participavam das reuniões dos órgãos onde estavam inseridos, bem como prevenir-se de instabilidades causadas por mudanças no cenário político, e, consequentemente, a formalização provocou um aumento de patrocinadores à rede de empoderamento das equipes técnicas que já possuíam histórico de metodologias de inovação, conforme apontam Faria et al. (2017).

Cumpre mencionar que, ao verificar o número de colaboradores que formam a rede de inovação, disponível no site oficial do Inovagov (2018), percebemos que o setor público conta com uma quantidade expressiva em comparação com os outros setores, sendo 66 do setor público, 18 do setor privado, nove do terceiro setor e cinco do setor acadêmico.

Infere-se, ainda, da plataforma do Inovagov (2018), como a rede realiza suas ações, que são as que se seguem:

- implementando conjuntamente projetos de inovação, que envolvem a cocriação de soluções e apoio mútuo;

- $\quad$ promovendo estudos, pesquisas, projetos e trabalhos conjuntos para solução de desafios e problemas de interesse comum;

- compartilhando ferramentas, práticas e conhecimentos referentes à inovação no setor público;

- $\quad$ gerando e compartilhando conteúdos sobre inovação nesta plataforma (Biblioteca e Blog) e em outros meios (Revista InovaGov); 
- realizando eventos e ações para difundir técnicas e práticas inovadoras na administração pública;

- $\quad$ estendendo aos servidores a possibilidade de participação em ações de capacitação e eventos promovidos pelas instituições da rede;

- $\quad$ promovendo atividades conjuntas de educação corporativa na modalidade presencial ou a distância.

Especificam, ainda, os benefícios que se alcança quando se atua em rede:

- discussão qualificada sobre os problemas e desafios da inovação no setor público e suas possíveis soluções;

- cocriação de soluções e apoio mútuo, aproveitando-se os diversos perfis e conhecimentos;

- compartilhamento de ferramentas e métodos para aceleração de projetos inovadores;

- maior facilidade na obtenção de patrocínio de projetos inovadores;

- $\quad$ portfólio único de projetos inovadores, com identificação de riscos de duplicação de esforços e de desperdícios de recursos;

- disseminação da cultura de inovação.

- cofinanciamento de projetos e eventos;

- oportunidade para mentoria colaborativa e troca de experiências;

- construção de exemplos pioneiros de inovação no âmbito federal para serem replicados em outros órgãos.

Diante do exposto, pode-se afirmar que houve grande avanço na criação de uma rede de inovação que proporciona compartilhamento de experiências, discussões sobre novas ideias e formas de diminuir os riscos de fracassos das inovações, motivação e fomento de ações e projetos inovadores dentro da metodologia de gestão das organizações; por outro lado, é perceptível que é necessário um trabalho contínuo, motivado e de qualidade, com diálogos de conscientização com as equipes para que, de forma engajada e interessada, se possa discutir e elencar novos desafios ou reformulá-los, no intuito de manter a rede de inovação com resultados positivos. 


\section{ASPECTOS DAS EXPERIÊNCIAS DA REDE DE INOVAÇÃO NO SETOR PÚBLICO}

Muito se debatem, hoje em dia, no meio científico e político, os produtos e processos inovadores que podem gerar efeitos positivos no setor público. No Brasil, essa demanda por inovação que produz benefícios para os órgãos governamentais e para a população tem crescido cada vez mais e alguns estudos têm como objetivo elucidar o impacto no cotidiano dessas instituições e seus vários aspectos com base nas experiências.

A busca por uma gestão pública assertiva, que ofereça uma prestação de serviços públicos com qualidade, eficiência e economia, é um dos maiores desafios a serem enfrentados na atualidade, que demanda análise de alternativas que atendam a necessidade da sociedade de maneira inovadora, rápida e constante. Observase que a inovação tecnológica é considerada como um importante meio capaz de propiciar processos mais adequados e eficazes nas organizações. Portanto, a gestão pública visa a um alcance maior de efetividade, agilidade e redução da complexidade burocrática.

Nesse aspecto, apresentam-se três exemplos de inovações que possibilitam maior eficiência e eficácia nas instituições públicas, sendo amplamente reconhecidos nacional e internacionalmente como ferramentas tecnológicas: Sistema Eletrônico de Informação (SEI), Dataviva e o Sistema Mineiro de Inovação (SIMI).

\subsection{SISTEMA ELETRÔNICO DE INFORMAÇÃO - SEI}

Neste cenário, o Sistema Eletrônico de Informação (SEI) é um importante sistema utilizado peloa Poderes Judiciário, Legislativo e Executivo. O SEI é uma ferramenta desenvolvida pelo Tribunal Regional Federal da $4^{\mathrm{a}}$ Região (TRF4) como alternativa para a gestão eletrônica de processos e documentos que promovem a eficiência administrativa, sendo cedido gratuitamente aos demais órgãos e entidades da esfera pública municipal, estadual e federal.

Assim, Cária e Laia (2018) afirmam que as informações criadas e utilizadas pelo setor público precisam ser gerenciadas efetivamente, complementando que os esforços direcionados anteriormente aos sistemas para a realização da gestão documental não foram bem-sucedidos para a administração pública, sendo essa 
demanda suprimida com a criação e implantação do SEI.

O SEI proporciona práticas inovadoras no setor público, eliminando substancialmente o uso de papel, ocasionando tramitação mais célere de pastas, documentos e processos com assinatura eletrônica via computador, tablete ou celular, disponibilizando assim informações seguras, confiáveis e oportunas. Para Padilha (2011), é fundamental a utilização de informações que possuem um controle adequado sobre cada sistema, pois, dessa maneira, atingem-se os resultados mais favoráveis com menores desperdícios.

Cavalcante et al. (2017) definem inovação no processo com o objetivo de aumentar a eficiência e eficácia dos processos organizacionais internos para facilitar a produção e entrega de bens e serviços aos cidadãos, e inovação no processo tecnológico como novos elementos introduzidos na operação de serviços de uma organização para produzir seus produtos ou restituir seus serviços aos cidadãos.

Devido aos seus aspectos inovadores e práticos de gestão de processos, o SEI traz grandes impactos positivos na modernização da gestão pública, como a economicidade, a eficiência no âmbito da administração e a transparência dos processos públicos. Cária e Laia (2018) concluem ainda que o SEI, além de viabilizar a institucionalização de uma política de gestão documental, é sustentada por elementos que conformaram um desenho institucional, sendo um sistema flexível suficientemente para abarcar qualquer processo da administração, com quaisquer documentos que precisem ser tramitados.

\subsection{DATAVIVA}

Nem sempre as informações referentes à economia brasileira estiveram disponíveis e acessíveis para a população, e, até mesmo, para outros entes do órgão governamental. Além disso, quando os dados eram disponibilizados, o acesso geralmente era restrito ou altamente complexo para entendimento.

Diante desse cenário, surge o projeto Dataviva, uma plataforma desenvolvida pelo governo de Minas Gerais no ano de 2013, com parceria entre diversos órgãos e entidades governamentais, entidades privadas e o laboratório de pesquisa MIT Media Lab, onde se utilizam bases de dados de todo setor formal da economia, 
como os Ministérios do Trabalho e Previdência Social (MTPS) e do Desenvolvimento, Indústria e Comercio Exterior (MDIC), com o objetivo de apoiar o planejamento econômico e social de diversas regióes.

Cavalcante et al. (2017, p. 119) explicitam que "[...] nesse sentido, muitos têm afirmado que a inovação pode contribuir não só para o crescimento econômico, mas também para melhorar a qualidade e eficiência do serviço público ao aumentar a capacidade governamental em resolver problemas".

De acordo com Pessoa, Freitas e Borges (2016, p. 3, grifo do autor), “[...] a plataforma (Dataviva) explicita conexões que estavam 'perdidas' nos dados, possibilitando ao usuário entender de maneira inédita o desenvolvimento das atividades econômicas no país".

Relata-se ainda que o projeto visa a (i) incorporar, na cultura de gestão estratégica, conhecimento necessários ao uso de uma plataforma aberta constituída de dados, métodos e processos para o estudo das cadeias de valor presentes na economia, (ii) destacar a agenda de inovação do Estado, focando nas instituições de pesquisa, universidades e agentes públicos, (iii) implantar, em órgãos de planejamento estratégico, métodos e técnicas de análise de cadeias de valor presente na economia, das tecnologias a elas subjacentes e das possibilidades de inovação oferecidas pelo contexto no mercado mundial e (iv) identificar e analisar as estruturas produtivas e suas interações nos municípios, com a finalidade de manter um crescimento para a economia de forma sólida (PESSOA; FREITAS; BORGES, 2016).

Barrence, Gomes e Freitas (2014) afirmam que o Dataviva é um caso de sucesso mundial no esforço de tornar dados públicos não apenas abertos, mas, principalmente, visíveis. Pelo fato de fornecer dados oficiais sobre a atividade econômica, exportações e localidades, a plataforma ajuda a criar uma forte conexão entre o setor público e o privado, favorecendo o desenvolvimento econômico regional.

Os autores ainda esclarecem que "inovador em termos tecnológicos, teóricos e de acesso a dados oficiais, o DATAVIVA é uma ferramenta fundamental para quem quer conhecer a economia brasileira e explorar seu potencial de crescimento".

Referente à plataforma, Pessoa, Freitas e Borges (2016) esclarecem que "ao inovar na forma de disponibilizar informações oficiais do Brasil, a ferramenta permite 
que o cidadão explore o universo dos dados de forma sustentável, fundamentada, simples e intuitiva". A plataforma Dataviva ganhou, em 2014, o Prêmio Excelência em Governo Eletrônico (Prêmio E-gov) da Associação Brasileira de Entidades Estaduais de Tecnologia da Informação e Comunicação (ABEP).

\subsection{SISTEMA MINEIRO DE INOVAÇÃO - SIMI}

O Sistema Mineiro de Inovação (SIMI), instituído em 2006, tem por finalidade promover a inovação no Estado de Minas Gerais, tornando-se uma ferramenta estratégica que reúne, em um só local, as principais informações sobre empreendedorismo, ciência, tecnologia e inovação, permitindo, assim, ações de apoio à inovação no Estado.

A iniciativa do SIMI “[...] tem por objetivo facilitar a interação e integração dos atores de inovação no Estado, identificando as fases da pesquisa, tecnologia e inovação. Esse processo simplifica a busca por parceiros no estágio em que cada um se encontra" (SISTEMA MINEIRO DE INOVAÇÃO, 2014, p. 1), além de identificar e facilitar a conexão de atores que proporcionam a inovação, como empreendedores, pesquisadores, empresas, instituições e governo.

Vilela, Neves e Pereira (2008, p. 5) esclarecem que “[...] o SIMI possibilita tanto o ambiente necessário para o diálogo e a interação entre os atores de inovação, quanto o sistema de governança entre as instituições de fomento da inovação, as empresas, as instituições acadêmicas e o governo [...]".

Os autores ainda afirmam que umas das "[...] diferenças do SIMI em relação aos outros sistemas de inovação diz respeito à sua capacidade de pautar políticas públicas. Um dos principais benefícios de um sistema de inovação é a contribuição dos agentes envolvidos na definição da política pública de inovação". (VILELA; NEVES; PEREIRA, 2008, p. 5).

Nesse aspecto, o sistema visa a possibilitar a interação de agentes governamentais, empresariais e acadêmicos que fomentam a inovação no âmbito estadual, portanto, funcionando "[...] como uma bússola que guiará os processos inovadores pelos melhores caminhos” (SISTEMA MINEIRO DE INOVAÇÃO, 2014). 


\section{CONSIDERAÇÕES FINAIS}

$\mathrm{Na}$ observação obtida pela exploração das principais características dos experimentos de inovação existentes no âmbito da administração pública, identificou-se que a inovação no setor público impõe uma série de limitações que precisam ser superadas para se tornar efetivo.

A respeito da pergunta inicial, percebe-se que as práticas utilizadas pela administração pública são relevantes para celeridade e transparência dos processos. Para ampliar a efetividade desse processo, faz se necessário inserir a inovação na rotina de trabalho da administração pública, considerando suas práticas e aplicações como ferramenta do cotidiano, sobretudo, em termos de infraestrutura dos atores envolvidos.

No contexto da era digital e tecnológica, o setor público deve se tornar protagonista na criação e execução de processos e produtos inovadores. Isso significa ampliar a capacidade da administração em pautar políticas públicas que beneficiam todos os agentes envolvidos.

Nesse aspecto, é fundamental estimular a inovação no setor público, por meio de ações objetivas envolvendo parcerias entre administração pública, pesquisadores, universidades e demais atores envolvidos.

Como limitação da pesquisa, considerou-se a utilização de sistemas inovadores já implantados e amplamente divulgados pelas instituições públicas, tendo a literatura brasileira pouca gama de informações referente a processos inovadores que não sejam divulgados por esses institutos. Contudo, em função da pesquisa realizada neste artigo, os resultados obtidos permitiram explorar as principais características da inovação existente no âmbito da administração pública.

Para futuras pesquisas, sugerem-se análises que investiguem diversos processos inovadores que permitem aprofundar e complementar o conhecimento da área. Há de se estimular pesquisas que auxiliem a compreensão das peculiaridades dos modelos inovadores regionais e dos sistemas que auxiliem a propagação de pensamento inovador, de modo que as pesquisas realizadas contribuam para outros estudos na área, uma vez que os mapeamentos desses processos inovadores ainda possuem pequena literatura disponível para análise. 


\section{REFERÊNCIAS}

BARRENCE, A.; GOMES, D. T.; FREITAS, E. E.. Big data em 100 milhões de visualizações abertas sobre a economia brasileira. Harvard Business Review, mar. 2014.

BRANDÃO, S. M.; BRUNO-FARIA, M. de F. Research on public sector innovation: analysis of scientific literature in national and international journals in the area of administration. Revista de Administração Pública, v. 47, n. 1, p. 227-248, fev. 2013.

CÁRIA, I. M. S.s; LAIA, M. M. de. A implantação do sistema eletrônico de informações no Centro de Serviços Compartilhados da Secretaria de Estado de Planejamento e Gestão de Minas Gerais. Belo Horizonte: ANPAD, 2018.

AGUNE, R. et al. Gestão do conhecimento e inovação no setor público: dá para fazer. São Paulo: Secretaria de Planejamento e Desenvolvimento Regional, 2014. Disponível em: http://igovsp.net/sp/da-pra-fazer.pdf. Acesso em: 10 out. 2018.

CASTRO, D. Gestão da inovação no setor público: um estudo de caso na regional centro sul de Minas dos Correios. Lavras: UFLA, 2016.

CAVALCANTE, P.; CAMÕES, M.; CUNHA, B. Q.; SEVERO, W. R. (org.). Inovação no setor público: teoria, tendências e casos no Brasil. Brasília: IPEA, 2017. Disponível em: $\quad$ http://www.ipea.gov.br/portal/images/stories/PDFs/livros/ivros/171002 inovacao_no_setor_publico.pdf. Acesso em: 10 out. 2018.

DIAS, I. de M. Práticas de inovação em gestão pública. In: AGUNE, Roberto et al. Gestão do conhecimento e inovação no setor público: dá para fazer. São Paulo: Secretaria de Planejamento e Desenvolvimento Regional, 2014. cap. 6, p. 118-155. Disponível em: http://igovsp.net/sp/da-pra-fazer.pdf. Acesso em: 10 out. 2018.

HELAL, D. H.; DIEGUES, G. C. Do patrimonialismo ao paradigma gerencial: paradoxos na administração pública de Caeté-MG. APGS, Viçosa, MG, v. 1. n. 1, p. 23-45, jan./mar. 2009.

FARIA, Y. de; ITABORAHY, F. B.; PALVARINI, B. C.; ENDO, I. C.; RONCARATTI, L. S. 
Experiências da Rede de Inovação no Setor Público (INAGOV). In: CAVALCANTE, Pedro; CAMÕES, Marizaura; CUNHA, Bruno Queiroz; SEVERO, Wilber da Rocha (org.). Inovação no setor público: teoria, tendências e casos no Brasil. Brasília: IPEA, 2017. cap. 13, p. 241-248. Disponível em: http://www.ipea.gov.br/portal/ images/stories/PDFs/livros/livros/171002_inovacao_no_setor_publico.pdf. Acesso em: 10 out. 2018 .

GIL, A. C. Métodos e técnicas de pesquisa social. 5. ed. São Paulo: Atlas, 1999.

HALVORSEN, T. On innovation in the public sector. In: HALVORSEN, T.; HAUKNES, J.; MILES, I. RØSTE, R. On the differences between public and private sector innovation. Oslo: NIFU STEP, 2005.

HOFFMAN, M. G.; KLUMB, R. Inovação no setor público e evolução dos modelos de administração pública: o caso do TRE-SC. Cadernos de Gestão Pública e Cidadania, São Paulo, v. 21, n. 69, p. 84-100, maio/ago. 2016.

INOVAGOV. Rede de inovação no setor público. Quem somos. Disponível em: http://inova.gov.br/quem-somos/. Acesso em: 10 out. 2018.

MULGAN, G.; ALBURY, D. Innovation in the public sector. London: Prime Minister's Strategy Unit, 2003.

ORGANIZAÇÃO PARA A COOPERAÇÃO E DESENVOLVIMENTO ECONÓMICO. Manual de Oslo: diretrizes para coleta e interpretação de dados sobre inovação. 3. ed. Paris: OCDE, 2005.

OLIVEIRA, A. N.; CARNEIRO, A. de F.; CIDADE-KONZEN, I. G. do N.; SILVA NETO, J. M. da. Discussões sobre inovação no setor público. In: CONGRESSO NACIONAL DE EXCELÊNCIA EM GESTÃO, 11., 2015, Rio de Janeiro. Anais [...]. Rio de Janeiro: Universidade Federal Fluminense, 2015.

PADILHA, F. B. O controle interno como ferramenta de gestão: um estudo de caso em uma empresa de serviços. 2011. Trabalho de Conclusão de Curso (Especialização em Controladoria e Gestão Empresarial) - Departamento de Ciências Administrativas, Contábeis, Econômicas e da Comunicação, Universidade Regional do Noroeste do Rio Grande do Sul, Ijuí, RS, 2011. 
PESSOA, R. M.; FREITAS, E. E.; BORGES, T. B. Dataviva: Plataforma de Visualização de Dados Públicos Socioeconômicos Brasileiros. In: CONGRESSO CONSAD DE GESTÃO PÚBLICA, 9., 2016, Brasília. Anais [...]. Brasília: CONSAD, 2016.

POTTS, J. Innovation by elimination: a proposal for negative policy experiments in the public sector. Innovation: Management, Policy \& Practice Journal, v. 12, n. 2, p. 238-248, 2010.

SANTOS, F. J. S. D.; SANO, H. Inovação no setor público: um olhar sobre os estudos brasileiros. Interface - Revista do Centro de Ciências Sociais Aplicadas, v. 13, n. 2, p. 33-48, 2016.

SCHUMPETER, J. A. Teoria do desenvolvimento econômico: uma investigação sobre lucros, capital, crédito, juro e o ciclo econômico. São Paulo: Nova Cultural, 1997.

SISTEMA MINEIRO DE INOVAÇÃO. Trilha Mineira da Inovação. 2014. Disponível em: $<$ http://simi.org.br/trilhamineiradainovacao/about $>$. Acesso em: 5 out. 2018.

SPINK, P. A inovação na perspectiva dos inovadores. In: JACOBI, Pedro; PINHO, José Antonio (org.). Inovação no campo da gestão pública local: novos desafios, novos patamares. Rio de Janeiro: FGV, 2006.

VILELA, E. F.; NEVES, H. P.a; PEREIRA, R. A. O. Gestão participativa e Web 2.0 no sistema mineiro de inovação (SIMI). In: CONGRESSO CONSAD DE GESTÃO PÚBLICA, 1., 2008, Brasília. Anais [...]. Brasília: CONSAD, 2008.

Recebido em: 26/03/2019

Aceito em: 06/06/2019 